\title{
Effects of Traditional Processing Methods on the Mineral and Antinutrients of Fresh and Squeezed-Washed Bitter Leaf
}

\author{
Agomuo Jude Kelechi, Okache Thomas Akobi, Taiwo Mayomi, Anamege Lynda Chioma \\ Department of Food Science and Technology, Federal University, Dutsinma, Nigeria
}

Email address:

tokache@fudutsinma.edu.ng (O. T. Akobi)

\section{To cite this article:}

Agomuo Jude Kelechi, Okache Thomas Akobi, Taiwo Mayomi, Anamege Lynda Chioma. Effects of Traditional Processing Methods on the Mineral and Antinutrients of Fresh and Squeezed-Washed Bitter Leaf. Journal of Food and Nutrition Sciences.

Vol. 5, No. 5, 2017, pp. 192-197. doi: 10.11648/j.jfns.20170505.15

Received: April 25, 2017; Accepted: May 4, 2017; Published: October 24, 2017

\begin{abstract}
Bitter Leaf is a vegetable that is widely consumed and cherished in South-Eastern Nigeria. Palm oil, Potash, Salt and boiling process was used in the squeeze-washing at 3 pre-processing methods of squeeze-wash and periods of 3 to 8 minutes. The percentage retention and losses of mineral and antinutrient increased simultaneously during squeeze-washing. Copper, magnesium, calcium and antinutrient had retention of 55 to $100 \%$ for samples squeezed-washed with palm oil than the other squeeze- washed samples. This could be due to rigidity of the cells which did not allow much nutrient leached into the squeezed leaf/water; whereas, the loss of mineral and antinutrients was practically of the same magnitude (27.3 to $80.5 \%)$ in all the samples. Loss of minerals and antinutrients was observed to be influenced directly by the cause-and-effect of disintegration changes which usually leads to softening due to the severity of the squeeze-washing on the bitter leaf instead of cellular composition or level of minerals and antinurients initially present. The results are discussed in relation to traditional commercial practice of bitter leaf processing.
\end{abstract}

Keywords: Biter Leaf, Palm Oil, Salt, Patash

\section{Introduction}

Green leafy vegetable are important as food both from economic and nutritional standpoint [9]. Leafy vegetables contain nutrients which can be absorbed by the body to be used as regulatory and protective material [39]. They occupy an important place among the food crops as they provide adequate amount of many vitamins and minerals for humans [15]. Leafy vegetables represent inexpensive but high quality nutritional sources for the poor segment of the population, especially where malnutrition is widespread [29]. They contain phytochemicals which have both positive and detrimental effects. Some of these phytochemicals are antinutrients that reduce in bioavailability of vitamins and minerals [12]. Some the forms of these phytochemicals have been used in folk medicine to improve some human health conditions. [18] stated that the potassium content of leafy vegetables is good in the control of diuretic and hypertensive complications, because it lowers arterial blood pressure.
Leafy vegetables contain low calories and negligible quantities of utilize energy. Hence, they are ideal for obsessed people who can satisfy their appetite without consuming much carbohydrate. Some leafy vegetables are known to lower blood pressure [17]. These leaves can do much to preserve mother's health and pass on strength to the foetus in pregnant and breast feeding women [38].

Vernonia amygdalina, commonly known as bitter leaf mostly occurs wild, though it could be cultivated. It is widely consumed in mostly Central African countries both by humans and animals. It is consumed by a large proportion of the Cameroonian population, though its cultivation is limited to the southern parts of the country [41]. In Nigeria, its consumption is mainly by some Igbo speaking areas in the South-Eastern States [26]. It is known as Oriwo in Edo, ewuro in Yoruba, Shuwaka in Hausa and Onugbo in Igbo [20, 21].

Studies on the nutritional composition of Vernonia found 
its nutritional content to conform to the results obtained for green leafy vegetables. It contains phosphorous, ascorbic acid, iron, and phosphorous, ascorbic acid, iron, $\beta$-carotene, calsium, water, and fibre as well as other nutrients, though it is low in fat [37]. Vernonia amygdalina contains antinutritional factors much as alkaloids, saponins, tannins, sesquiterpere lactones (e.g vernodalin Vernolepin), steroid glucosides (vernoniosides), flavonoids, glycosides (vernomin) and sterols which cause it bitterness [36, 10]. Bitter leaf contains appreciable high contents of a-acids, iso-a acid and essential oils which can be used as hop substitutes in beer brewing [34].

This work evaluated the retention and loss of minerals and antinutrient in fresh and squeeze- washed bitter leaf using traditional method of processing.

\section{Materials and Methods}

\subsection{Sources of Materials}

The fresh bitter leaf vegetables were bought randomly from at a local three different sellers' market in Umuahia, Abia State. This market was chosen because of its peculiarity with the processing and selling of bitter leaf.

Sample Preparation

The fresh bitter leaves were sorted, de-stalked and rinsed in water to remove dust and dirt, and were left to drain. They were then divided into six parts. The six parts were individually subjected to different local processing methods.

The first processing method was normal squeeze-washing. The bitter leaves were squeeze- washed by breaking, squeezing and rinsing of the sample to remove bitterness. The process of squeezing and rinsing was done in 3 preprocessing rounds; 8mins each, for the first and second intervals while the third interval is for 5 mins making a total of 21 mins. Rinsing was done when enough foam was formed that prevented successful squeeze- washing.

The second processing method was squeeze -washing and boiling. The sample was squeeze-washed using the same procedure as described in the first process but not as intense as was done to the sample subjected to only squeeze washing. In this process, squeeze- washing was mild as it was for only $14 \mathrm{mins}$ (3 pre-processing rounds of $8 \mathrm{mins}$, 3mins.) And this made it possible. For the bitter leave samples to retain high level of bitterness. The mildly squeeze- washed bitter leaves were then introduced into boiling water in an iron pot to boil for 2 minutes at $115 \mathrm{O} \mathrm{C}$.

The third treatment involves the addition of $5 \mathrm{~g}$ of salt while squeeze-washing the bitter leaf. The process lasted for 11 mins after 3 rounds of squeeze-washing.

The fourth treatment was squeeze washing with the addition of $5 \mathrm{~g}$ of grounded potash. Also this process lasted for 11 mins. At three rounds of squeeze -wash. Another treatment involves the addition of $5 \mathrm{ml}$ of Palm oil is added in order to retain the fibrous tissue of the leaves.

The unprocessed sample served as the control. Before any of these samples was analyzed, it was reduced in size by pounding it in a mortar with pestles.

\subsection{Determination of Mineral Content of Bitter Leaf}

The minerals were determined by atomic absorption photometry technique by [22].

\subsubsection{Calcium, Potassium and Sodium Determination}

The ash of each sample obtained was digested by adding $5 \mathrm{ml}$ of $2 \mathrm{M} \mathrm{HCL}$ to the ash in the crucible and heat to dryness on a heating mantle. $5 \mathrm{ml}$ of $2 \mathrm{M} \mathrm{HCL}$ was added again, heat to boil, and filtered through a Whatman No. 1 filter paper into a $100 \mathrm{ml}$ volumetric flask. The filtrate was made up to mark with distilled water and made ready for reading of concentration of Calcium, potassium and sodium on the Jenway Digital Flame Photometer (PFP7 Model) using the filter corresponding to each mineral element.

The concentration of each of the element was calculated using the equation:

$$
\% \text { Ca or } \% \mathrm{~K} \text { or } \% \mathrm{Na}=\frac{\text { Meter Reading }(\mathrm{MR}) \times \text { Slope } \times \text { Dilution factor }}{1000}(1)
$$

\subsubsection{Determination of $\mathrm{Mg}, \mathrm{Cu}, \mathrm{Mn}, \mathrm{Fe}, \mathrm{Zn}$ Using Buck $200 \mathrm{AAS}$}

The digest of the ash of each sample above as obtained in calcium and potassium determination was washed into $100 \mathrm{ml}$ volumetric flask with deionised or distilled water and made up to mark. This diluents was aspirated into the Buck 200 Atomic Absorption Spectrophotometer (AAS) through the suction tube. Each of the trace mineral elements was read at their respective wavelengths with their respective hollow cathode lamps using appropriate fuel and oxidant combination.

\subsection{Determination of Antinutritional Factors}

The antinutritional factors were determined using the method of Association of Official Analytical chemist [1].

\subsubsection{Phytate Determination}

Two grams $(2 \mathrm{~g})$ of each sample was weighed into $250 \mathrm{ml}$ conical flask. Each sample was soaked in $100 \mathrm{mls}$ of $2 \%$ Hydrochloric acid in the conical flask for 3 hours. This was filtered through a double layer of hardened filter paper. $50 \mathrm{mls}$ of each filtrate was placed in $0.50 \mathrm{ml}$ conical flask and $107 \mathrm{mls}$ distilled water was added in each case to give proper acidity. $10 \mathrm{mls}$ of $0.3 \%$ Ammonium thiocyanate (NH4SCM) solution was added into each solution as indicated. This was titrated with standard iron (III) chloride solution which contained $0.000195 \mathrm{~g}$ iron per $\mathrm{ml}$. the end point was slightly brownish- yellow which persists for 5 minutes. The \% phytate was calculated using the equation:

$$
\% \text { Phytic acid }=\frac{\text { Titre value } \times 0.00195 \times 1.19 \times 100 \times 3.55}{\text { Wt.of Sample }}
$$

\subsubsection{Oxalate Determination}

Two grams $(2 \mathrm{~g})$ of each sample was boiled in $40 \mathrm{ml}$ of water for 30 minutes in a reflux condenser. $10 \mathrm{mls}$ of $20 \%$ $\mathrm{Na} 2 \mathrm{CO} 3$ was added and boiled for another 30 minutes. The 
liquid extract was filtered and washed with hot water until the waster does not show any alkaline reaction and concentrated and filtered into a small volume and cooled. With constant stirring, HCL (1:1 molar ratio)was added in drops until the final acid concentration after neutralization is about $4 \%$ at which stage a heavy precipitate appears (which is allowed to flocculate). The extract was carefully filtered into a $250 \mathrm{ml}$ flask and made up to mark. It was kept overnight, and then supernatant liquid was filtered through a dry filter paper in a dry beaker.

An aliquot of this filtration was put in a beaker and diluted with water to $200 \mathrm{ml}$ and made to ammonic acid and then acidified with laconic Acid. In the cold media, $10 \mathrm{ml}$ of a $10 \%$ calcium chloride solution was added and stirred well for calcium oxalate precipitate to appear, and allowed to settle overnight. The clean supernatant liquid was carefully decanted off through Whatman No. 42 filter paper, without disturbing the precipitate. The precipitate was dissolved in HCI (1:1) oxalic acid and precipitated by adjusting the $\mathrm{pH}$ with ammonium hydroxide solution. The content was boiled and allowed to settle overnight. Oxalic acid was determined by titrating against $0.05 \mathrm{~N} \mathrm{KMnO} 4$ solution. equation:

$1 \mathrm{ml}$ of $\mathrm{KMnO}_{4}=0.00225$ anhydrous Oxalic acid

$$
\% 0 x a l i c \text { acid }=\text { titre value } \times \frac{0.00225}{2} \times \frac{100}{1}
$$

\subsection{Statistical Analysis}

The mineral and antinutrient compositions were determined by different methods. The data obtained were subjected to analysis of variance (ANOVA) to determine any significant difference at $5 \%$ level $(\mathrm{p}<0.05)$ using SPSS version 16 and was reported as means of three replicate.

\section{Discussion}

The values of minerals analyzed showed that there were losses of minerals when bitter leaf was squeeze - washed. Squeeze-washing with salt, potash, palm oil and that squeeze-washed and boiled also caused significant $(\mathrm{p}<0.05)$ reductions in the $\mathrm{K}, \mathrm{Ca}, \mathrm{Mg}, \mathrm{Na}, \mathrm{Fe}$ and $\mathrm{Zn}$ contents of the vegetable. Similarly, [35] reported significant reductions $(\mathrm{p}<0.05)$ in $\mathrm{K}, \mathrm{Ca}, \mathrm{Mg}, \mathrm{Na}, \mathrm{Fe}$ and $\mathrm{Zn}$ contents of blanched, cooked tender and matured cassava leaves. [40] also reported reductions in the $\mathrm{Fe}$ and $\mathrm{Zn}$ contents of scent leaf (Ocimum gratissum), bitter leaf (vernonia amygdalina), bush okro and green pepper (piper guineense) that were used in soup preparation. this is in conformity with reports of [25] that blanching and cooking significantly reduced $(\mathrm{p}<0.05)$ the $\mathrm{K}$, $\mathrm{Ca}, \mathrm{Na}, \mathrm{Zn}$ and Fe contents of Amaranth, tomatoes, fluted pumpkin, gnetum vegetable, spinach, slippery vine and cocoyam leaves..

Calcium is probably mainly associated with the pectic substances of the cell wall and could significantly influence texture. Its high content in vegetables especially fruit vegetables is important in strengthening of bones and teeth in man and animals [8] and necessary for blood clothing [25].
The value of calcium content of the bitter leaf sample $(13.11+0.99 \mathrm{mg} / 100 \mathrm{~g})$ obtained (Table4.3) is similar to the value reported for $V$. amgydalina by [13]. The value is lower than the values reported for $V$. amgydalin and $M$. charantia by [7], though it is higher than the Ca value reported for A. hydrides by [3]. [28, 7] opined that macro-minerals are required in amounts greater than $100 \mathrm{mg} / 100 \mathrm{~g}$. [23] reported the value of calcium content of bitter leaf in this study is close to these values recorded for vegetables and hence high enough to meet this requirement and could therefore be said to be a good source of the mineral.

The availability of $\mathrm{Ca}$ in body fluids and in water shows that it is water soluble [23]. This explains the significantly lower $(\mathrm{p}<0.05)$ value of the calcium content in the squeeze washed bitter leaf. [14] reported a 50 percent loss of calcium in $V$. colorata subjected to squeeze- washing, which was due to leaching of the calcium into washing water. [24] stated that blanched leafy vegetable (Amaranthus conentus L.)Had lower calcium content than the fresh leaf, which was probably due to leaching losses of the calcium into the water. The squeeze- washed and boiled bitter leaf had the lower value, which is due to the influence of heat in increasing dissolution of the solutes in water, enhanced by differences in the concentration of the mineral in the leaf and boiling water.

Magnesium is an active component of several enzymes. It is also a constituent of bones, teeth, enzymes co-factors and a constituent of chlorophyll [28]. The magnesium content of the studied bitter is similar to that reported for A. hybidus by [3]. It is high enough to meet the RNI adult intake of $0.3 \mathrm{~g} /$ day $(300 \mathrm{mg} / \mathrm{day})$ for the mineral [23]. It is therefore a good source of the mineral.

Magnesium like most other minerals (inorganic substances) is soluble in water. Thus, some of the magnesium contained in the leafy vegetable will leach into the washing water. This explains the lower values of the magnesium content of the squeeze- washed bitter leaf.

Squeeze- washing and boiling caused more significant reduction $(p<0.05)$ in the magnesium content of bitter leaf. This was due to increased dissolution of the mineral into boiling water. [30] stated that cooked trifoliate yam had lower magnesium content than that of raw trifoliate yam. The sample squeeze -washed with potash had the highest result. This can be attributed to high value of magnesium in potash. Potassium in the blood is life -threatening problem [5]. Potassium is a primary electrolyte and a major cation inside the cell and low potassium in the blood is life -threatening problem [4]. Potassium functions in acid-base balance, regulation of osmotic pressure, muscle contraction, particularly the cardiac muscle. Its deficiency affects the collecting tubules of the kidney [42]. The potassium content of the bitter leaf in this study is similar to that reported of $V$. amygdalin and $M$. charanti by [7]. It is however; lower than that reported for Amaranthus cruentus L. by [24]. [23] reported the RNI of potassium as $350 \mathrm{mg} /$ day. The potassium content of bitter leaf in this study is close to the values reported for Amaranthus hybridus by [3] and has potential of meeting this requirement with increased consumption of the 
quantity of the leafy vegetable daily. Therefore, bitter leaf could serve as a good source of potassium. The result shows a significant reduction $(\mathrm{p}<0.05)$ of the mineral with normal squeeze -washing treatment of the bitter leaf. This is due to leaching loss of the mineral in to the washing water. Potassium being an important mineral in the body fluids is quite soluble in water. Hence the result obtain was expected.

Squeeze- washing and boiling of $V$. amygdalina resulted in a higher significant reduction $(\mathrm{p}<0.05)$ in the mineral potassium. The result obtained for potassium was similar to that obtained for calcium probably due to dissolution of the potassium into the boiling water.

Sodium is a principal cation in extracellular fluids. It regulates plasma volume. It is involved in $\mathrm{Na}+\mathrm{k}-+$ Tpase maintenance membrane potentials [18]. The sodium content of the bitter leaf in this study $12.001 \mathrm{mg} / 100 \mathrm{~g}$ (Table 4.3) is lower than that reported for $V$. amygdalina and $M$. charantia by [7] and for Amaranthus cruentus by [24]. This value is however, higher than that reported for $A$. hybridus leaves by [3]. The sodium content of the studied bitter leaf is too low to meet the RNI of sodium (1600mg/day) according to [23] and therefore must be sourced from other sources, especially salt.

Like other mineral elements, it is readily soluble in water and some sodium contents of bitter leaf leached into the washing water. The squeeze-washed and boiled Vernonia amygdalina showed the highest loss of sodium, which is due to dissolution losses into the boiling water enhanced by heating. The sample squeezed-washed with salt recorded the highest value and this is due to the salt concentration used in the process. The iron content of $V$. amygdalina obtained in this work is between 6.01 and $21.39 \mathrm{mg} / 100 \mathrm{~g}$ and compares favorably with those obtained by [13] for $V$. amygdalina and $V$. calvonana var bitter as well as those obtained for $A$. hybridus, L. occidentalis and Lycopersicon esculentum [25]. Iron is an integral constitutuent of haeme, of haemoglobin, myoglogbin and cytochromes [11] it is also important in the transport of oxygen in blood. The iron content of bitter leaf in this study could be considered adequate when viewed against an RDA of $8 \mathrm{mg} \mathrm{Fe}$ /day of men of ages 19 years and above, and women over 40 years, $18 \mathrm{mg} \mathrm{Fe} /$ day for girls and women between the ages of 11 and 50 [16]. Its deficiency causes anaemia [6]. The iron content of the squeeze- washed, which was due to leaching losses of the mineral into washing water. This effect was observed by [14]. The squeeze-washed bitter leaf with palm oil had the lowest content of Fe.

Squeeze -washing and boiling retained the highest amount of $\mathrm{Fe}$ in the bitter leaf. This was probably due to a higher concentration of $\mathrm{Fe}$ in the boiling water than in the bitter leaf, which dissolved from the iron pot, as solute diffusion.

Zinc is among the mineral that has the lowest value in the samples of squeeze-washed bitter leaf analyzed with a $2.18 \mathrm{mg} / 100 \mathrm{~g}$ (Table 1). This value compares favourably with the value reported for Amaranthus hybidus [3] as well as with that reported for $V$. amygdalina by [7]. [23] states an RNI of $9 \mathrm{mg}$ of $\mathrm{Zn} /$ day. The zinc content of bitter leaf studied is good enough to meet the RNI of $\mathrm{Zn}$ and therefore is a good source of the mineral. Zinc is required for cell replication and gene expression [43] as well as for tissue repair, wound healing and reticular development. It is also integral constituent of insulin [26, 28]. Zinc deficiency in developing countries is becoming a growing concern because it has been shown that zinc deficiency is related not only to decrease growth, but also to increase morbidity and impaired immune function [19].

The sample squeeze-washed with palm oil had the lowest retention of zinc while the highest zinc retention was observed in the normal squeeze -washed bitter leaf. Zinc like most other inorganic mineral elements exist in ionic forms for their involvement in biological functions and are therefore readily soluble in water.

The processing operation of squeeze -washing leaches out some of the zinc in the bitter leaf into the washing water.

A highly significant $(\mathrm{p}<0.05)$ reduction of zinc was observed for squeeze -washed with palm oil sample, probably due to dissolution of zinc into the boiling water.

The copper content of vegetable $(0.85-0.19 \mathrm{mg} / 100 \mathrm{~g})$ were higher than the result $(0.06 \mathrm{mg}-0.21 \mathrm{mg} / 100 \mathrm{~g})$ reported by [33] and that of Occimum gratissimum [2] $1.8 \mathrm{mg} / \mathrm{day}$ for women, respectively. Therefore, the vegetables are needed to enable the absorption and mobilization of iron and its utilization in haemoglobin synthesis.

Manganese is a metallo-enzyme involved in pyruvate metabolism and also required for glucose utilization. The values obtained $(0.99-2.11 \mathrm{mg} / 100 \mathrm{~g})$ were slightly lower than that of Occimum gratissmum reported by [2]. Thus, adequate consumption would meet the needs of the body since adequate intake for Manganese is $2.3 \mathrm{mg} /$ day.

From Table 2, the values of Oxalate in these vegetables (3.74\%-1.26\%) were higher than pterocarpies soyauxii and Genuetum africanum [12] and slightly above the toxic level of $2.5 \mathrm{~g}$ reported by [27]. Oxalates are known to form insoluble complexes with $\mathrm{Ca}, \mathrm{Mg}$ and $\mathrm{Fe}$ thereby interfering with utilization of these mineral elements [27]. However, since the vegetable are consumed after the squeeze-washing process, there appears to be no danger of toxicity arising from oxalate.

Although, literatures available on phytate content of green leafy vegetables are limited: as reported by [34]. High values of phytate $(20.8$ and $19.0 \mathrm{mg} / 100 \mathrm{~g})$ have been reported for bitter leaf and fluted pumpkin leaf, respectively [31]. Ingestion of $2.5 \mathrm{~g}$ or more of phytate per day cause reduction in bioavailabity of $\mathrm{Ca}, \mathrm{Fe}$ and $\mathrm{Zn}$ [20]. The mineral profile of the five samples showed that the values of the mineral varied depending on the substance used in the squeezing-washing process. Moreso, the low values of antinutritional contents in the different samples make them safe for consumption in high quantity and give these vegetables a place in the food list for recommendation, appropriate for good health.

\section{Conclusion}

Retention and losses of minerals and antinutrients in the bitter leaf samples varied from 23 to $61 \%$, and 27.3 to $80.5 \%$ respectively. The sample squeeze-washed with palm oil 
exhibited a high (55-100\%) mineral uptake (Calcium, copper, magnesium, e.t.c) than the remaining samples (38 to $65 \%$ ), although the range of losses remained the same (27.3 to $80.5 \%$ ) in all sample. By implication, losses of minerals and antinutrients depended on changes induced by the intensity of the squeeze-washing process to disintegrate the vegetable structurally rather than composition of each vegetable samples. Furthermore, nutrient gain of some of the samples is dependent on the compositions of the material of squeezewashing (palm oil) and retention of its cellular structure. It is recommended that palm oil be used in the squeeze-washing of bitter leaf for better nutrient retention.

\section{References}

[1] A. O. A. C. (2005) Official methods of Analysis of Analytical Chemists.

[2] Adepoju, O. T. and Oyewole, E. O (2008). Nutritional importance and micronuteient potentials of two nonconventional indigenious Green leafy vegetables from Nigeria. Agric. j. 3 (5): 362-365.

[3] Akubugwo, I. E., Obasi, N. A., Chinyere, G. C. and Ugbofu, A. E. (2007). Nutritional and chemical value of Amarathus hybridus L. leave from Afikpo, Nigeria. African Journal of Biotechnology 6 (24): 2833-2839.

[4] Allen, L. H. (2003). Intervention for micronutrient deficiency control in developing countries: past, present and future. Journal of Nutrition, 133: 3875-3878.

[5] Allison, A. (2001). The possible role of vitamin K deficiency control in the pathogenesis of Alzeimer's disease and in augmenting brain damage associated with cardiovascular diseases. Medical Hypothesis 57 (2): 151-155.

[6] Awoyinka, A. F., Abegunde, V. O. and Adewusi, S. R. A (1995). Nutrient content of young cassava leaves and assessment of their acceptance as a green vegetable in Nigeria. Plant foods for Human Nutrition 47: 21-28.

[7] Ayoola, P. B., Adeyeye, A. and Onawuni, O. O. (2001). Trace elements and major minerals evaluation of Spondias mombin, $V$. amygdalina and Momordica charantia leaves. Pakistan journal of nutrition 9 (8): 755-758.

[8] Balakbir, A., Butz, J. M., and Romero, L. (1998). Yield and fruit quality of pepper (Capsicum annum L.)in response to Bioregulator. Horticultural Science 3. 85-87.

[9] Bolaji, P. T., komolafe G. O. and Alli, E. (2008). Drying characteristics of selected local Nigerian vegetables, Nigerian Food journal 26 (1): p 138.

[10] Buttler, G. W. and Bailey, R. W. (1973). Chemistry and Biochemistry of Herbage. Academic Press, London. P. 63.

[11] Chandra, R. K. (1990). Micro nutrients and Immune Functions: An Overview. Annals of new York Academy of Science. 587-9-16.

[12] Chima, C. E. and Igyor, M. A. (2007). Micronutrients and anti-nutritional contents of selected tropical vegetable grown in south-Eastern Nigeria. Nigerian Food Journal. 25 (1): 111117.
[13] Ejoh, A. A., Djuikwo, V. N., Gouado, I. and Mbofung, C. M. (2007a). Nutritional components of some non-conventional leafy vegetables consumed in Cameroon. Pakistan Journal of Nutrition 6 (6): 712-717.

[14] Ejoh, A. A., Djuikwo, V. N. gouado, I. and Mbofung, C. M (2007b) Effects of the method of processing and preservation on some quality parameters of the non- conventional leafy vegetables. Pakistan of Nutrition 6 (2): 128 -133.

[15] Fasuyi, A. O. (2006) Nutritional potentials of some tropical vegetable meals; chemistry characterization and function properties. African Journal of biotechnology 5 (1): 49.

[16] FNB. Food and Nutrition Board, Institute of Medicine (2001). Dietary Reffence intakes for Vitamin A, Vitamin K, Arsenic, Boron, Molybdenum, Nickel Sillicon, Vanadium and Zinc. Washton D. C. Standing Committee on scientific Evaluation of Dietary Reference intakes national-Academic press.

[17] Fugile, L. (2000). Moringa, Natures medicine Cabinet is natural for tropics.

[18] Hays, V. W and Swenson, M. J (1985) minerals and Bones in : Dukes' Physiology of Domestic animals. 10th Edition pp. 449-466.

[19] Huffman, G. (1998). Zinc can reduce pediatric respiratory infections American family Physician 58: p2127.

[20] Igile, G. O., Oleszyek, W., Burda, S. and Jurzysta, N. (1995). Nutritional assessment of Veronomia amygdalina leaves in growing mice. Journal of Agriculture and Food Chemistry 43: 2162-2166.

[21] Ijeh. I., Nwugo, V. o and Obidoa, O. (1996). Comparative studies on the nutritive Pytochemical and antimicrobial properties of two verties of Vernonia. Plant Pros comm. 1: 7175. james, C. S. (1995) Analytical chemistry of Foods. Chapman and Hallm, New York pp. 28 and 405.

[22] Kupehan, S. M., Hemingway, R. J., karim, A. and Werner, D. (1969) Tumor inhibitors 47: vernodalin and vernomygdin, two New Cytotoxic Chemistry 34: 908-3911.

[23] Lean M. N., (2006). Vitamins and other bioactive food constituents in: Food Science, Nutrition and Health (7th edition). Edward Hodder Ltd, London pp198-216.

[24] Makobo, N. O., Shoko, M. D. and Mtatia, T. A (2010). Nutrient content of amaranth (Amaranthus crunetus L.) under different processing and preservation methods. World journal of Agricultural sciences 6 (6): 639-643. Malhotra, V. k. (1998) Biochemistry for student (10th Edition). Jaypee Brothers Medical Publishers Ltd, New Dehi, india.

[25] Mepba, H. D., Eboth, F. and Bonigbo, D. E. B. (2007) Effects of processing treatments on the nutritive composition and consumer acceptance of some Nigerian edible leafy vegetables. African Journal of Food Agriculture, nutrition and development (71): 1-8.

[26] Morah, G. N. and Obiegbuna, J. E. (2002). The effect of different pre-washing and washing treatment on some chemical and sensory properties of bitter leaf vegetable. Nigerian Food Journal 20: 52-57.

[27] Munro, A. and Basssir, O. (1969). Oxalate in nigeria vegetables. W. Afr. J. Society of Nigeria. Abakaliki, November, 14th-17th p. 111-114. 
[28] Murray, R. K. Granner, D. k., meyes, P. A, Rodwell, V. W. (2000). Harpers biochemistry 25th Edition McGraw- Hill health Profession Division, USA.

[29] Nnamani, C. V., Oselebe, H. O. and Okorie, E. O. (2007) Ethonobotany of indigenous leafy vegetables of Izzi Clan in Ebonyi State, Nigeria. In: proceeding of 20th annual national Conference of Biotechnology Society of Nigeria. Abakaliki, november, 14th-17thpp. 111-114.

[30] Obiakor, P. N. (2007) Effect of different processing techniques on the nutrients and anti-nutrients composition of trifolioate yam (Doscorea dumentonum) Flours. Nigerian Journal of Nutritional Sciences 28 (2): 68-74.

[31] Oguntona, T. (1998). Green leafy vegetables. In: osagie, A. U. and Eka, O. U. (Eds) Nutritional Quality of plant foods. Amik Press, Benin City Nigeria 5: 120-133.

[32] Ogutona, T. (1985) Loss of thiamine in some Nigerian vegetables. A paper presented at the $1^{\text {st }}$ International Conference of Food and health, held in Salsamaggire Parma, Italy, p. 20.

[33] Okafor, J. C. (1979). Edible indigenous woody plants in the rural ecosystem (D. U. U. Okali, ed). Proceeding of M. A. B. Workshop on the Nigerian Rainforest Ecosytem. University of Ibadan, Nigeria.

[34] Okafor, N. and Anichie, G. N. (1983) West African Hop Substitutes for sorghum lager Beer. Dist. Int. 13 (1): 20-23, 31

[35] Oladunmoye, O. o., Ojeniyi, S. and Bankole, A. O. (2005) Mineral composition of tender and matured cassava leaves after home cooking procedures. Proceedings of 29th Annual conference of the Nigerian institute of food science and technology held at Ebonyi state university, Abakaliki pp. 151152 .

[36] Ologunde, m. O., Ayorinde, F. O., Shephard, R. K., Afolabi, O. A. and Oke, O. L. (1992)Sterols of seed oils of Vernonia galanesis, Amaranthus cruentu, Amaranthus caudatum, Amaranthus hybridus and Amaranthus hypoochrondriacus grown in the humid tropics. Journal of food and agriculture 58: 221-225.

[37] Oshodi, A. A. (1992). Comparison of Proteins, minerals and Vitamin C content of some dried leafy vegetables. Pakistan journal of science and industrial research 35: 267-269.

[38] Price, M. (1995). Moringa tree in Natural Nutrition for Tropics. Sierra Sunrise books Missouri 1: pp. 12-15.

[39] Saidu, A. N. and Jideobi, N. G. (2009). The proximate and elemental analysis of some leafy vegetables grown in Minna and Environs. Journal of Applied Science Environment and Management 13 (4): 21-22.

[40] Selman, J. D. (1994). Vitamin retention during blanching of vegetables. Food Chemistry 49: 144-147.

[41] Singh, G., Kawatra, A. and Sehgal, S. (2001). Nutritional composition of selected Green Leafy vegetables, herbs and carrots. Plant foods for human nutrition 56: 359-364.

[42] Streeten, D. H. P. and Williams, E. V. (1952). Loss of cellular potassium as a cause of intestinal paralysis in dogs. Journal of Physiology 118: 149-170.

[43] Szabo, G. Chanvan, S., Mandrekar, p., Catalano D. (1999) Acute Alcoholic. 